\title{
Acceptor-free Alcohol Dehydrogenation by Recyclable Ruthenium Catalyst
}

\author{
Won-Hee Kim, In Soo Park, and Jaiwook Park*
}

\section{Supporting Information}

Synthesis of ruthenium catalyst 1: $\mathrm{RuCl}_{3} \mathrm{xH}_{2} \mathrm{O}$ (Precious Metals Online: $52 \mathrm{mg}, 0.25 \mathrm{mmol}$ ), $(\text { sec-BuO })_{3} \mathrm{Al}(2.5 \mathrm{~g}, 10 \mathrm{mmol})$ and ethanol $(1.2 \mathrm{~mL}, 20 \mathrm{mmol})$ were added into $25 \mathrm{~mL}$ round bottom flask equipped with condenser. After the mixture was stirred at $100{ }^{\circ} \mathrm{C}$ for $1 \mathrm{~h}$ to give black suspension, water $(2.0 \mathrm{~mL})$ was added quickly. The reaction mixture was stirred further for $30 \mathrm{~min}$ at $100{ }^{\circ} \mathrm{C}$. The resulting black solid was filtered, washed with acetone, and dried in the air at room temperature to give $\mathbf{1}$ as grey powder $(0.74 \mathrm{~g} ; 2.5 \mathrm{wt} \%$ of Ru).

Dehydrogenation of 1-phenylethanol: In a $50 \mathrm{~mL}$ flask equipped with a grease-free high vacuum stopcock and connected to a bubbler, 1 (121 mg, $3.0 \mathrm{~mol} \% \mathrm{Ru})$ and 1-phenylethanol (122 $\mathrm{mg}, 1.00 \mathrm{mmol})$ were mixed with dry toluene $(5 \mathrm{~mL})$ under argon atmosphere. The reaction mixture was heated at $80{ }^{\circ} \mathrm{C}$ for $10 \mathrm{~h}$. The catalyst was filtered and washed with acetone. Solvent was removed from the filtrate under reduced pressure to give analytically pure acetophenone (120 mg, $>99 \%$ ).

Recycling of 1: A suspension of 1 (121 mg, $3.0 \mathrm{~mol} \% \mathrm{Ru})$ and 1-phenylethanol (122 mg, 1.00 $\mathrm{mmol})$ in toluene $(5 \mathrm{~mL})$ was stirred at $80{ }^{\circ} \mathrm{C}$ for $10 \mathrm{~h}$ in a flask equipped with a grease-free high vacuum stopcock and connected with bubbler under Ar. After the reaction, 1 was recovered by filtration and was reused after washing with acetone and drying in the air at room temperature. 
Characterization of 1: The catalyst $\mathbf{1}$ was characterized by transmission electron microscopy (TEM). A distinct fibrous morphology is shown in the TEM images (Figure 1 and 2). The catalyst 1 was also characterized by energy dispersive X-ray spectrometer (EDX) and X-ray photoelectron spectroscopy (XPS). EDX showed the presence of Ru (Figure 3), but Cl was not detected. The XPS data for 1 was collected on an ESCALab250 spectrometer operating at $15 \mathrm{kV}$ and $20 \mathrm{~mA}$ at a pressure of about $5 \times 10^{-10}$ mbar with $\mathrm{Al}_{\mathrm{K} \alpha}$ radiations as the excitation source $(h v=1486 \mathrm{eV})$. Figure 4 shows the $\mathrm{Ru} 3 \mathrm{~d}$ spectrum of $\mathbf{1}$. Although the $\mathrm{Ru} 3 \mathrm{~d}$ signal is obscured by the $\mathrm{C}$ 1s signal of a carbon contaminant, the spectrum shows a doublet for two chemically different Ru entities with peak binding energies of $279.7 \mathrm{eV}\left(\mathrm{Ru} 3 \mathrm{~d}_{5 / 2}\right)$ and $284.0 \mathrm{eV}\left(\mathrm{Ru} 3 \mathrm{~d}_{3 / 2}\right)$, which confirms the presence of $\mathrm{Ru}(0)$ in catalyst $\mathbf{1}$. Meanwhile, the peak at $281.2 \mathrm{eV}$ suggests the presence of a Ru-O component, which probably results from oxidation of the ruthenium during preparing $\mathbf{1}$. The specific surface area of 1 was determined to be $424.7 \mathrm{~m}^{2} / \mathrm{g}$ by the $\mathrm{N}_{2}$ BET method at $77 \mathrm{~K}$. 


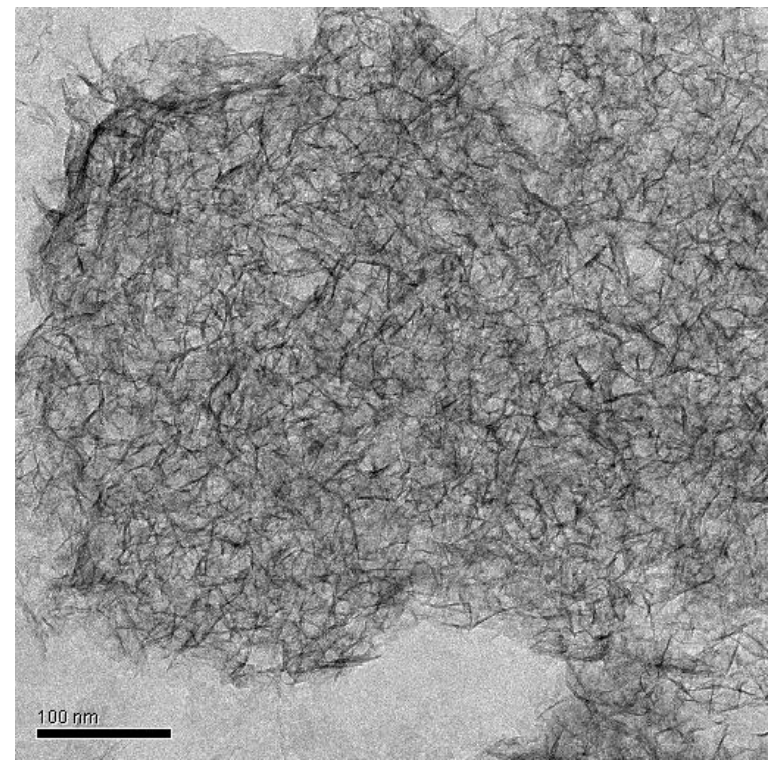

Figure 1. Low resolution TEM image of $\mathbf{1}$.

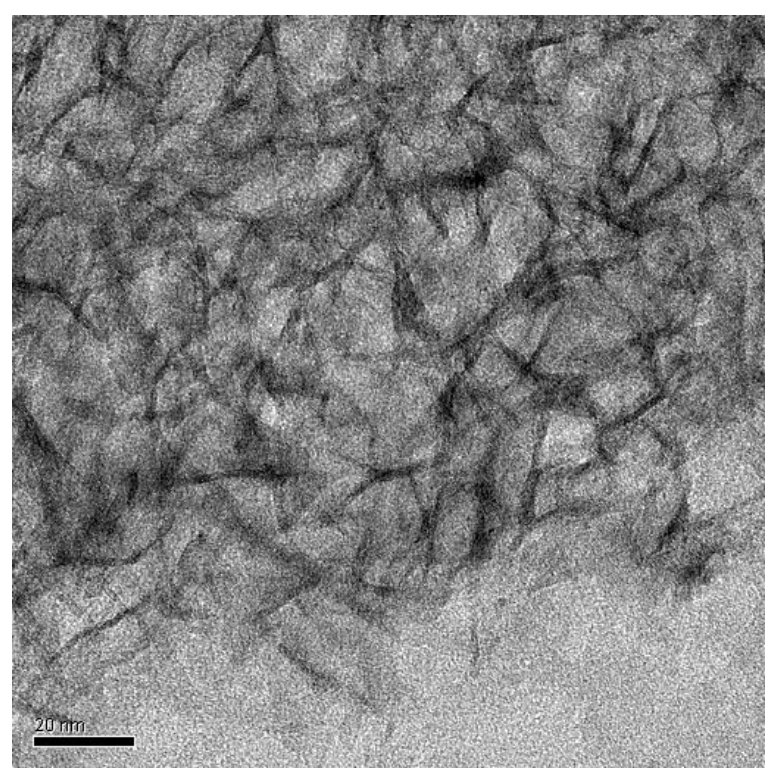

Figure 2. High resolution TEM images of $\mathbf{1}$. 


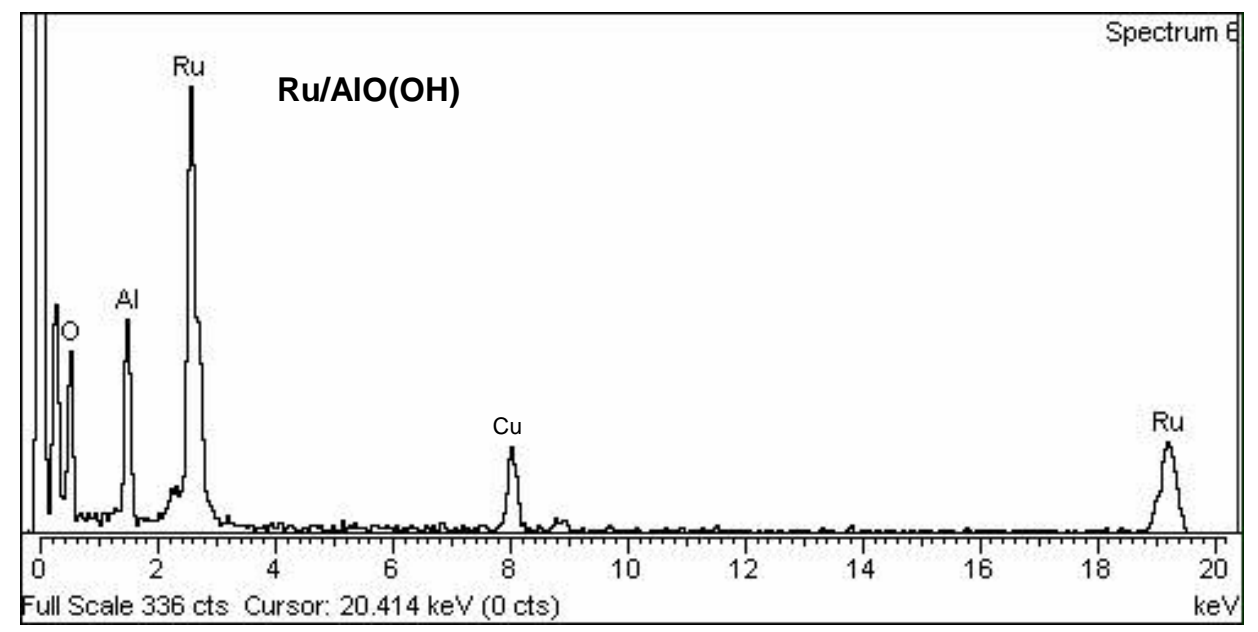

Figure 1. EDX analysis of $\mathbf{1}$.

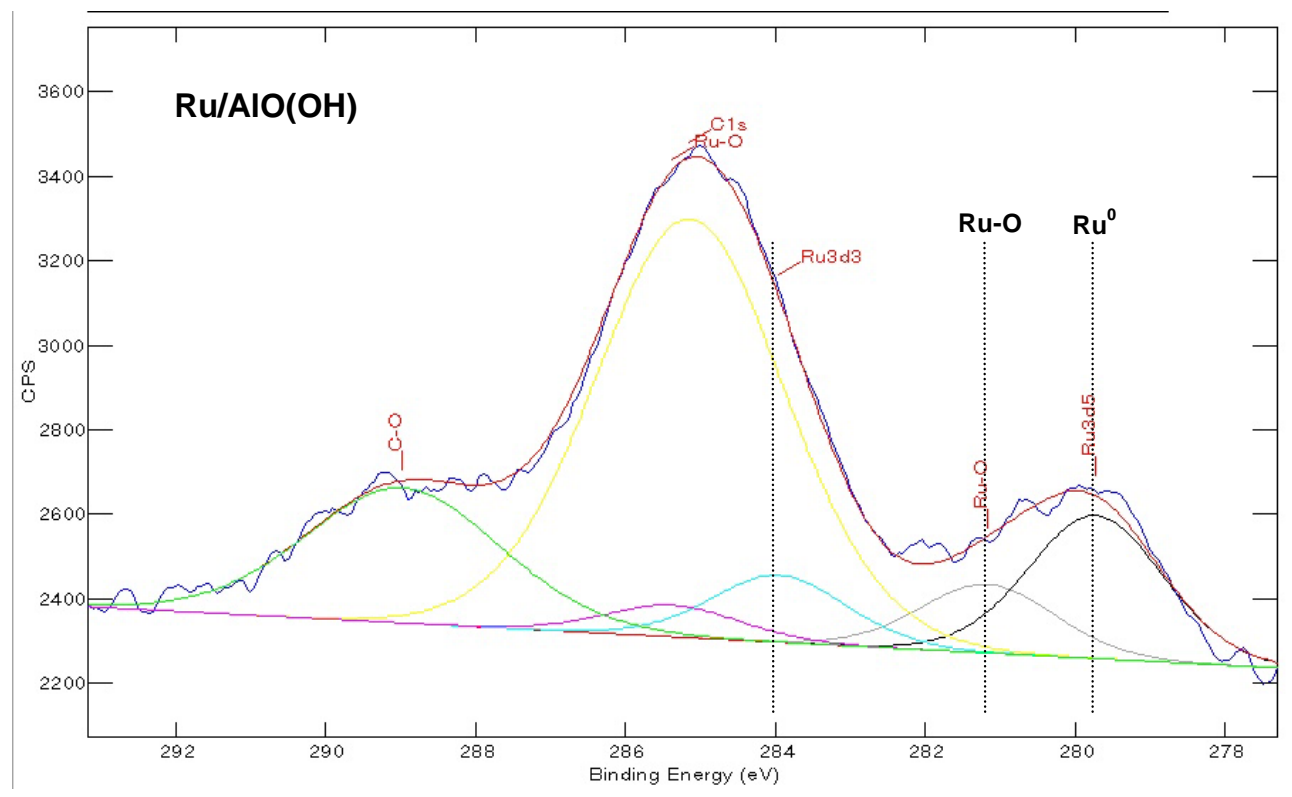

Figure 2. XPS spectra of $\mathbf{1}$. 